\section{Can ratio of neutrophil-to- lymphocyte count and erythrocyte sedimentation rate in diabetic foot infecti on predict osteomyelitis and/or amputation?}

Oktay Yapıcı, ${ }^{1}$ Hande Berk, ${ }^{1}$ Nefise Öztoprak, ${ }^{1}$ Derya Seyman, ${ }^{1}$ Alper Tahmaz, ${ }^{1}$ Alparslan Merdin ${ }^{2}$

${ }^{1}$ Infectious Diseases and Microbiology Clinic, ${ }^{2}$ Internal Medicine Clinic, Antalya Education and Research Hospital, Antalya, Turkey

\section{Abstract}

The aim of this study was to search for any relations between the neutrophil-tolymphocyte ratio (NLR) and the development of osteomyelitis and the need for amputation in patients with diabetic foot infection (DFI). All data included DFI patients who were hospitalized in our Infectious Diseases Clinic between 2012 and 2015 and who were classified according to International Classification Disease Code System. 75 patients were analyzed in the study. The DFI patients were stratified into 3 groups of whom had amputation procedure, whom had only debridement/drainage procedure and whom had any surgery procedure. Sidac post hoc analysis was used to perform the effects of NLR, C-reactive protein, erythrocyte sedimentation rate and glycosylated hemoglobin on the surgery procedure status. The DFI patients were also stratified into two another separate group for another analysis to search for the effect of NLR values on the development of osteomyelitis. The mean value of NLR in the amputated patients' group $(15.7 \pm 10.3$ was significantly higher than those with debridement procedure $(9.9 \pm 5.6)$ and those without any surgery $(6.0 \pm 2.8)(\mathrm{P}=0.001)$. NLR values were also found significantly higher in patients with osteomyelitis in the second analysis $(\mathrm{P}=0.004)$. In this study, the NLR was found to have a predictive value on the development of osteomyelitis and on the progression to amputation in patients with DFI.

\section{Introduction}

Irritation, inflammation, ischemia, neuropathy and infections are important factors in diabetic foot pathophysiology. ${ }^{1,2}$ Studies showed that changes in the amount of lymphocytes and neutrophils play an important role in inflammation and infection. . $^{3,4}$ NLR is cheap and it can easily be calculated by using the peripheral blood count. The NLR which is an indicator of immune response and systematic inflammation, has a prognostic effect on many diseases including coronary artery disease ${ }^{5,6}$ and cancer. ${ }^{7,8}$ In the literature, few studies showed that NLR was meaningful for the diagnosis of diabetes and for the prediction of development of diabetic complications.9,10 Whether or not NLR can predict the prognosis in diabetic foot infection is unclear. Therefore, the aim of this study was to investigate any relations between the NLR and the development of osteomyelitis and the need for amputation in patients with DFI.

\section{Materials and Methods}

All data included DFI patients who were hospitalized in our Infectious Diseases Clinic between 2012 and 2015 and who were classified according to International Classification Disease (ICD-10) Code System. 25 patients whom had amputation procedure, 25 patients whom had only debridement/drainage procedure, and 25 patients whom had any surgery procedure were included in the study. Imaging methods, physical examination and/or laboratory methods were used to put the diagnosis of DFI. Totally, 75 patients were analyzed in this study. NLR, CRP, ESR and $\mathrm{HbA1c}$ values of the all patients were obtained from the medical records. Variance analysis and Sidak post hoc analysis were used to perform the effects of NLR, CRP, ESR and HbAlc on the surgery procedure status.

The DFI patients were also stratified into two another separate group for another analysis to search for the effect of NLR values on the development of osteomyelitis. We used the same 75 patients for both of the two different analysis. The groups for this second analysis were stratified as the patients with osteomyelitis and the patients without osteomyelitis.

Statistical analysis was performed by using SPSS software version 22.0 (IBM, USA). P value $<0.05$ was accepted as significant.

\section{Results}

A total of 75 patients [males: 54 (72\%) females: $21(28 \%)$ ] were included in the study. Seventy two percent of the patients
Correspondence: Oktay Yapıc1, Department of Infectious Diseases and Clinical Microbiology, Antalya Education and Research Hospital, 07100 Antalya, Turkey. Tel.: +90.242.2493425 - Fax: +90.242.2494462. E-mail: yapicio@hotmail.com

Key words: Neutrophil to lymphocyte count; diabetic foot infection; osteomyelitis; amputation.

Contributions: the authors contributed equally.

Conflict of interest: the authors declare no potential conflict of interest.

Received for publication: 19 November 2016 Revision received: 30 January 2017.

Accepted for publication: 5 February 2017.

This work is licensed under a Creative Commons Attribution-NonCommercial 4.0 International License (CC BY-NC 4.0).

(C) Copyright O. Yapicl et al., 2017

Licensee PAGEPress, Italy

Hematology Reports 2017; 9:6981

doi:10.4081/hr.2017.6981

were male and the mean age of the all patients was $60.9 \pm 11.6$ years. $100 \%(n=25)$ of the all patients whom had amputation had osteomyelitis, $68 \%(n=17)$ of the all patients whom had only debridement/ drainage procedure had osteomyelitis, and $44 \%$ $(n=11)$ of the all patients whom had any surgery procedure had osteomyelitis. The mean values of NLR, CRP, ESR and HbA1c on admission were $10.60 \pm 8.0,151.57 \pm 98.9$ $\mathrm{mg} / \mathrm{L}, 78.5 \pm 25.6 \mathrm{~mm} / \mathrm{h}$ and $9.3 \pm 2.3 \%$, respectively.

The mean value of NLR in the amputated patients' group $(15.7 \pm 10.3)$ was significantly higher than those with debridement procedure $(9.9 \pm 5.6)$ and those without any surgery $(6.0 \pm 2.8)(\mathrm{P}=0.001)$. Mean CRP values of amputated patients (182 \pm 94.9) and patients with only debridement procedure (171.6 \pm 99.5$)$ were higher than patients without any surgery procedure (100.9 \pm 85.3$) \quad(\mathrm{P}=0.006)$. And mean ESR values of amputated patients $(93.5 \pm 19.1)$ and patients with only debridement procedure $(80.0 \pm 16.2)$ were higher than patients without any surgery procedure $(62.1 \pm 29.4)$ $(\mathrm{P}=0.001)$. On the other side, no significant difference were found among the $\mathrm{HbAlc}$ levels of the three group patients $(9.5 \pm 2.6)$, (10.0 \pm 2.6$) \quad(9.0 \pm 2.8), \quad$ respectively; $\mathrm{P}=0.425)$ (Table 1).

The initial NLR and ESR values were found significantly higher in patients with osteomyelitis $(\mathrm{P}=0.004, \mathrm{P}=0.001$, respectively) (Table 2 ). 
Table 1. Neutrophil-to-lymphocyte ratio, C-reactive protein, erythrocyte sedimentation rate and glycosylated hemoglobin values of the patients according to surgery procedure groups.

\begin{tabular}{lccccc} 
Mean values & $\begin{array}{c}\text { No-surgery, } \\
\text { Group } 1\left(\mathbf{n}_{1}=25\right)\end{array}$ & $\begin{array}{c}\text { Debridement/drainage, } \\
\text { Group 2 }\left(\mathbf{n}_{2}=25\right)\end{array}$ & $\begin{array}{c}\text { Amputation, } \\
\text { Group 3 }\left(\mathbf{n}_{3}=25\right)\end{array}$ & P-value & Post-hoc \\
NLR & $6.0 \pm 2.8$ & $9.980 \pm 5.6$ & $15.7 \pm 10.3$ & 0.001 & $3>2.1$ \\
CRP $(\mathrm{mg} / \mathrm{L})$ & $100.9 \pm 85.3$ & $171.6 \pm 99.5$ & $182.1 \pm 94.9$ & 0.006 & $3.2>1$ \\
\hline ESR $(\mathrm{mm} / \mathrm{h})$ & $62.1 \pm 29.4$ & $80.0 \pm 16.2$ & $93.5 \pm 19.1$ & 0.001 & $3.2>1$ \\
Hb1Ac $(\%)$ & $9.5 \pm 2.6$ & $10.0 \pm 2.6$ & $9.0 \pm 2.8$ & 0.425 & \\
\hline
\end{tabular}

NLR: Neutrophil-to-lymphocyte ratio; CRP: C-reactive protein; ESR: erythrocyte sedimentation rate; HblAc: glycosylated hemoglobin.

Table 2. Neutrophil-to-lymphocyte ratio and erythrocyte sedimentation rate values of patients with and without osteomyelitis.

\begin{tabular}{|c|c|c|c|}
\hline Mean values on admission & $\begin{array}{l}\text { Osteomyelitis absent } \\
\left(\mathrm{n}_{1}=22\right)\end{array}$ & $\begin{array}{c}\text { Osteomyelitis present } \\
\qquad\left(\mathrm{n}_{2}=53\right)\end{array}$ & P-value \\
\hline NLR & $6.0 \pm 3.7$ & $12.3 \pm 8.6$ & 0.004 \\
\hline ESR $(\mathrm{mm} / \mathrm{h})$ & $51.9 \pm 18.3$ & $89.6 \pm 19.3$ & 0.001 \\
\hline
\end{tabular}

NLR: Neutrophile-to-lymphocyte ratio; ESR: Erythrocyte sedimentation rate.

\section{Discussion}

DFI are serious problems in patients with diabetes, about $10 \%$ to $25 \%$ of patients with diabetes develop a foot ulcer and $60 \%$ of them are infected. ${ }^{11}$ Diabetic foot ulcers are the most common reasons for the hospitalizations and for the operations in patient with diabetes. ${ }^{12,13}$ Operations of diabetic patients lead to losses in both manpower and economy. ${ }^{12,13}$ DFI are classified as mild, moderate and severe according to the 2012 Clinical Practice Guideline for the Diagnosis and Treatment of Diabetic Foot Infections. ${ }^{14}$ Inflammatory markers such as CRP, ESR, procalcitonin could help to distinguish uninfected ulcers from infected ones. Especially ESR is an important laboratory marker in the diagnosis of DFO. ${ }^{15}$ It is well known that ESR levels higher than $70 \mathrm{~mm} / \mathrm{h}$ is one of the most powerful laboratory finding in the diagnosis of DFO. Van Asten et al. evaluated 24 DFO patients and found the mean initial ESR value as 78 $\mathrm{mm} / \mathrm{h} .{ }^{16}$ Ertugrul et al. reported that ESR $\geq 65 \mathrm{~mm} / \mathrm{h}$ together with a wound size $\geq 2$ $\mathrm{cm}^{2}$ were significant threshold levels for the diagnosis of DFO. ${ }^{17}$ In our study, the mean value of ESR was found as $89 \mathrm{~mm} / \mathrm{h}$. The ESR values of the patients with osteomyelitis were found significantly higher than the ESR values of the patients without osteomyelitis. Our findings were similar to the literature. ${ }^{16,17}$

Clinicians like to establish predictive factors for prognosis. In the last years, several investigators searched about NLR to use NLR in the diagnosis and in the prognosis of different infectious diseases such as brucellosis, tuberculosis, inactive hepatitis B. ${ }^{18-20}$ Loonen et al. reported that NLR could be used as a predictor for bloodstream infections in the emergency care units. ${ }^{21}$ Also, NLR was shown as a significant inflammatory marker in determining the severity, prognosis and differential diagnosis of bacterial pneumonia. ${ }^{22,23}$ Kahramanca et al. reported significantly higher NLR values in patients who required more than one debridement than in patients who required only one debridement. ${ }^{24}$ NLR might also be valuable for determining the prognosis of Fournier's gangrene. ${ }^{24}$ Lou et al. showed that post-treatment neutrophil-lymphocyte ratio independently predicts amputation in critical limb ischemia without operation. ${ }^{25}$ We showed that NLR was significantly higher in patients with osteomyelitis. We also found that high NLR value was independent risk factor for progression to amputation. Our results comply with the literature. $^{24,25}$ Lastly, NLR level might be a predictive biomarker for determining progression to amputation. Further studies are needed in this area to have an exact decision on establishing NLR as a prognostic factor.

\section{Conclusions}

Neutrophil-to-lymphocyte ratio value could be used as a cheap and simple biomarker to predict the development of osteomyelitis and/or amputation risk in patients with DFI. It may also be established as a prognostic factor with further studies.

\section{References}

1. Mark P, Sloven K. Foot problems in diabetes. Med Clin North Am 1998;82: 949-71.

2. Levin ME. Foot lesions in patients with diabetes mellitus. End Met Clin North Am 1996;25:447-45.

3. Lowsby R, Gomes C, Jarman I. Neutrophil to lymphocyte count ratio as an early indicator of blood stream infection in the emergency department. Emerg Med J 2015;32:531-4.

4. Uslu AU, Küçük A, Şahin A, et al. Two new inflammatory markers associated with Disease Activity Score-28 in patients with rheumatoid arthritis: neutrophil-lymphocyte ratio and plateletlymphocyte ratio. Int $\mathrm{J}$ Rheum Dis 2015;18:731-5.

5. Tamhane UU, Aneja S, Montgomery D, et al. Association between admission neutrophil to lymphocyte ratio and outcomes in patients with acute coronary syndrome. Am J Cardiol 2008;102:653-7.

6. Akın F, Ayça B, Çelik Ö, et al. Predictors of poor coronary collateral development in patients with stable coronary artery disease: neutrophil-tolymphocyte ratio and platelets. Anatol J Cardiol 2015;15:218-23.

7. Walsh SR, Cook EJ, Goulder F, et al. Neutrophil-lymphocyte ratio as a prognostic factor in colorectal cancer. J Surg Oncol 2005;91:181-4.

8. Li C, Wen TF, Yan LN et al. Postoperative neutrophil-to-lymphocyte ratio plus Platelet-to-lymphocyte ratio predicts the outcomes of hepatocellular carcinoma. J Surg Res 2015;194:46470.

9. Lou M, Luo P, Tang $R$, et al. Relationship between neutrophil-lymphocyte ratio and insulin resistance in newly diagnosed type 2 diabetes mellitus patients. BMC Endocrine Disorders 2015;15:9

10. Yilmaz H, Ucan B, Sayki M, et al. Usefulness of the neutrophil-to-lym- 
phocyte ratio to prediction of type 2 diabetes mellitus in morbid obesity. Diabetes Metab Syndr 2015;9:299-304

11. Ryskova L. Diabetic foot infections. Vnitr Lek 2015;61:587-91.

12. Laing P. The development and complications of diabetic foot ulcers. Am J Surg 1998;176:11-9.

13. Levin ME. Foot lesions in patients with diabetes mellitus. End Metab Clin North Am 1996;5:448-54.

14. Infectious Diseases Society of America. Clinical practice guideline for the diagnosis and treatment of diabetic foot infections. Clin Infect Dis 2012;54: e132-73.

15. Mutluoğlu M, Uzun G, İpcioğlu OM, et al. Can procalcitonin predict bone infection in people with diabetes with infected foot ulcers? A pilot study. Diab Res Clin Pract 2011;94:53-6.

16. Van Asten SA, Nichols A, La Fontaine $\mathrm{J}$, et al. The value of inflammatory markers to diagnose and monitor diabetic foot osteomyelitis. Int Wound $\mathrm{J}$
2017;14:40-5.

17. Ertugrul BM, Savk O, Ozturk B, et al. The diagnosis of diabetic foot osteomyelitis examination findings and laboratory values. Med Sci Monit 2009;15:CR307-12.

18. Olt S, Ergenç H, Açıkgöz SB. Predictive contribution of neutrophil/lymphocyte ratio in diagnosis of brucellosis. Biomed Res Int 2015;2015:210502.

19. Iliaz S, Iliaz R, Ortakoylu G, et al. Value of neutrophil/lymphocyte ratio in the differential diagnosis of sarcoidosis and tuberculosis. Ann Thorac Med 2014;9:232-5.

20. Ercin CN, Dogru T, Sertoglu E et al. Neutrophil-to-lymphocyte ratio as a predictor of fibrosis ininactive hepatitis B carriers. Eur J Gastroenterol Hepatol 2015;27:475-6.

21. Loonen AJ, de Jager CP, Tosserams J, et al. Biomarker and molecular analysis to improve bloodstream infection diagnostics in an emergency care unit. PLoS
One 2014;9:e87315.

22. De jager CP, Wever PC, Gemen EF, et al. The neutrophil-lymphocyte count ratio in patients with community acquired pneumonia. PLoS One 2012;7:e46561.

23. Bekdas M, Goksugur SB, Sarac EG, et al. Neutrophil/lymphocyte and C-reactive protein/mean platelet volume ratios in differentiating between viral and bacterial pneumonias and diagnosing early complications in children. Saudi Med J 2014;35:442-7.

24. Kahramanca S, Kaya O, Özgehan G, et al. Are neutrophil-lymphocyte ratio as effective as Fournier's gangrene severity index for predicting the number of debridements in Fournier's gangrene. Ulus Travma Acil Cerr Derg 2014;20: 107-12.

25. Luo H, Yuan D, Yang H, et al. Posttreatment neutrophil-lymphocyte ratio indepently predicts amputation in critical limb ischemia without operation. Clinics 2015;70:273-7. 